\title{
Characterisation of Phytochemical Constituents, Antioxidant and Anti Bacterial Properties of Red Strawberry against Klebsiella and Streptococcus
}

\author{
${ }^{1}$ Mr. G. Karthikeyan, ${ }^{2}$ Ms. M. Eureka, ${ }^{3}$ Ms. J. Amalsiya Bernath \\ ${ }^{1}$ Assistant Professor, Department of Biochemistry, Kongu Arts and Science College (Autonomous), Erode \\ 2,3 II - M.Sc Biochemistry, Kongu Arts and Science College (Autonomous), Erode
}

\section{ABSTRACT}

In plant kingdom, medicinal plants are main important resource for a variety of drug like emetics, anti-cancer and antimicrobials. Medicinal herbs are highly cultured in India, which includes more than 2000 species are present. Strawberry is soft fruit crop belongs to the family rasacea and genus fragaria and it contain excellent source of vitamins, potassium. Phytochemical constituents are identified in different extract (ethanol, acetone and aqueous). Secondary metabolites are used for the treatment of several diseases. Strawberry is the one of the best natural sources of antioxidants. Total antioxidant capacity was identified in all the extracts. Antibacterial activity of fragaria $x$ ananassa was evaluated against and Klebsiella and Streptococcus. From this study, concluded that the strawberry fruit have potent medicinal value.

\section{INTRODUCTION}

India has a rich culture of medicinal herbs and spices which includes about more than 2000 species and has a vast geographical area with high potential abilities for Ayurveda, unani, siddha traditional medicines [2]. A plant makes many chemical compounds for biological function and including defence against insects, fungi and herbivorous mammals. Plants have a great importance in our lives because they fulfil our basic needs for food, shelter, clothing, fuel, ornamentals, flavouring and medicine [8]. Plant-derived materials or products with therapeutic properties are known as herbal medicines, they may contain processed or raw ingredients from one or more plants that are beneficial for human health [20].

People use herbs to treat different diseases because they are cheap and effective, but doctors are often reluctant to prescribe them because of knowledge deficiency, real concerns [12]. In this study, traditional uses of plant are recognized as an effective way to discover further medicines. There are many parts in plants such as leaf, stem, fruits, buds, roots, etc., now we are ready to use the fruits of strawberry (fragaria $x$ ananassa) as medicinal herbs (Common name: Strawberry; Kingdom: plantae; Type: plant; Height: 10 - 12 inches ( 25-30cm); Bloom time: February; Fruit: Edible; Order: Rosales; Subfamily: Rosacea; Genus: Fragaria; Species: Fragaria $x$ ananassa) [9].

Strawberry (fragariax ananassa duch) is a soft fruit crop. Strawberries are unique with highly desirable taste, flavour, and excellent source of vitamins, potassium, fibre and sugars. As compared to other berry fruits, strawberries contain a higher percentage of vitamin C, Phenolics and flavonoids. Strawberry fruits are characteristics aroma bright red colour, juicy texture and sweetness [17]. It is consumed in large quantities, either fresh or in such prepared foods as preserves, fruit juice, ice creams and milk shakes. Nutritional and health aspects of fruit, they present alkaloids, flavonoids, carbohydrate, terpenoids, phenols makes the antioxidant potential as a well as protect some diseases as cancer or heart disorders.

The present investigation is aimed to characterize the medicinal effect of strawberry fruits using phytochemical analysis, antioxidant property and antibacterial activity [5].

\section{MATERIALS AND METHODS}

The present study deals with the study of phytochemical constituents, antioxidant capacity and antibacterial activity of fragaria $x$ ananassa fruit.

\subsection{Collection of Fruit}

The Fragaria $\mathrm{x}$ ananassa (Strawberry) fruit was collected from erode local market and stored in refrigerator. 


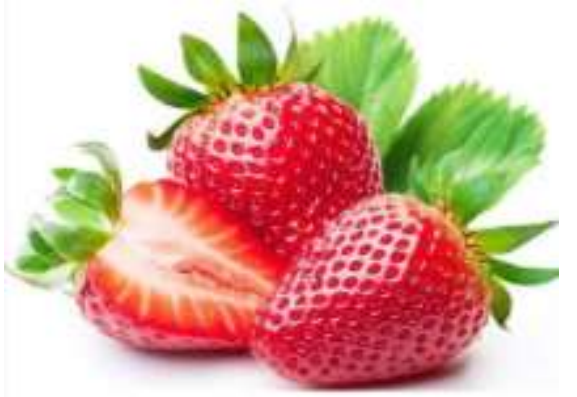

Figure 2.1: Image of sample used

\subsection{Preparation Of Extracts (1:10 ratio)}

Take 10 grams of freshly collected fruit sample and cut in to small pieces. Then grained with 100 ml selected solvents like Distilled water, Acetone and Ethanol. The contents were filtered through Whatmann filter paper and stored the filtrate in a respective conical flask with lid. This is used for the further analysis.

\subsection{Phytochemical Analysis}

2.3.1. Test for Alkaloids: To a few drops of extract, 2 drops of Mayer's reagent is added by the side of the test tube. A green coloured precipitate confirms the test as positive.

2.3.2. Test for Amino Acids: To a few drops of extract, few drop of Ninhydrin solution was added in a test tube. A characteristic blue colour indicates the presence of amino acids.

2.3.3. Test for Carbohydrates: To a few drops of extract, $2 \mathrm{ml}$ of molish's reagent is added. The mixture is shaken well and $2 \mathrm{ml}$ of Conc. $\mathrm{H}_{2} \mathrm{SO}_{4}$ is added slowly along the sides of the test tube and allowed to stand. A reddish ring formed at the junction of two solutions indicates the presence of carbohydrates.

2.3.4. Test for Tannins: To a few $\mathrm{ml}$ of extract, few drops of $1 \%$ Lead acetate is added. The mixture is shaken well. A yellowish precipitate indicates the presence of tannins.

2.3.5. Test for Phenols: To $2 \mathrm{ml}$ of extract, $3 \mathrm{ml}$ of ethanol and a pinch of ferric chloride are added. A greenish yellow colour appears which indicates the presence of Phenols.

2.3.6. Test for phytosterols: The extract was dissolved in acetic anhydride, heated to boiling, cooled and then $1 \mathrm{ml}$ of concentrated sulphuric acid was added along the side of the test tube. Appearance of Red, pink or violet colour at the junction of the liquids indicates the presence of phytosterols.

2.3.7. Test for Proteins: To a few $\mathrm{ml}$ of extract, few drop of Millon's reagent is added. White precipitate indicates the presence of protein.

2.3.8. Test for Saponins: To a few $\mathrm{ml}$ of extract, $20 \mathrm{ml}$ of distilled water is added in the test tube and the test tube is continuously shaken for 10 minutes. The foam formed confirms the presence of saponins.

2.3.9. Test for Terpenoids: To $2 \mathrm{ml}$ of extract, $2 \mathrm{ml}$ of acetic anhydride and Conc. $\mathrm{H}_{2} \mathrm{SO}_{4}$ is added. Formation of blue, green rings indicate the presence of terpenoids.

2.3.10. Test for Steroids: To $2 \mathrm{ml}$ of extract, $2 \mathrm{ml}$ of chloroform and $2 \mathrm{ml}$ of acetic anhydride is added reddish brown colour is formed. To this added $1 \mathrm{ml}$ of Conc. $\mathrm{H}_{2} \mathrm{SO}_{4}$. Formation of violet to blue green colour indicates the presence of Steroids.

\subsection{Antibacterial Activity (Bewer et al 1966)}

Agar well diffusion method was used to evaluate the antibacterial activity of extracts against test microorganism. Nutrient agar medium ( $\mathrm{pH} 7.0$ ) was prepared and autoclaved. It was allowed to cool up to $45^{\circ} \mathrm{C}$. Then it was seeded aseptically with $500 \mu \mathrm{l}$ of freshly prepared inoculum (106 colony forming unit, CFU) and immediately mixed. For inoculum preparation, the colonies of bacteria such as Klebsiella and Streptococcus were suspended in nutrient broth and turbidimetrically adjusted. $25 \mathrm{ml}$ of seeded nutrient agar media was transferred into each Petri plate and solidify. The organisms were spreaded in different petri plates. Four wells were made in each plate. Test solution of $50 \mu \mathrm{l}$ was poured into each respective well. These plates were incubated at $37^{\circ} \mathrm{C}$. After 24 hours of incubation, the diameter of the clear zones that showed inhibition of bacterial growth was measured in millimetre $(\mathrm{mm})$. Experiment was done in triplicate and mean value of zone inhibition was calculated with standard error.

\subsection{Test for Total Antioxidant Capacity}

Pipetted out $1.0 \mathrm{ml}$ of fragaria $x$ ananassa fruit sample extracts in a respective test tubes. The volume of all the test tubes is made up to $3 \mathrm{ml}$ with distilled water. $3 \mathrm{ml}$ of distilled water is taken in a blank. $1 \mathrm{ml}$ sodium phosphate, $1 \mathrm{ml}$ of 
Characterisation of Phytochemical Constituents, Antioxidant and Anti Bacterial Properties of Red Strawberry against Klebsiella and Streptococcus

ammonium molybdate and $1 \mathrm{ml}$ of sulphuric acid was added to all the test tubes. The blue colour was developed immediately read at $540 \mathrm{~nm}$. The amount of total antioxidant is expressed as $\mathrm{mg} / \mathrm{g}$ of fresh weight. Experiment was done in triplicate.

\section{RESULTS AND DISCUSSION}

\subsection{Phytochemical Screening}

In this study, the phytochemical constituents like alkaloids, amino acids, carbohydrates, tannin, phenols, phytosterols, protein, saponins, steroids and terpenoids were analysed. The above phytochemical constituents were equally present in all the extracts of fragaria $x$ ananassa fruit sample.

Table 3.1: Phytochemical screening of different extracts of fragaria $x$ ananassa

\begin{tabular}{|c|l|c|c|c|}
\hline \multirow{2}{*}{ S. No } & \multirow{2}{*}{ Phytochemicals } & \multicolumn{3}{|c|}{ Extracts } \\
\cline { 3 - 5 } & & Aqueous & Acetone & Ethanol \\
\hline 1 & Alkaloid & + & + & + \\
\hline 2 & Amino Acid & - & + & + \\
\hline 3 & Carbohydrates & + & + & - \\
\hline 4 & Tannins & + & + & + \\
\hline 5 & Phenols & + & - & + \\
\hline 6 & Phytosterols & + & - & - \\
\hline 7 & Proteins & - & - & - \\
\hline 8 & Saponins & - & - & - \\
\hline 9 & Terpenoids & - & + & + \\
\hline 10 & Steroids & & + & + \\
\hline
\end{tabular}
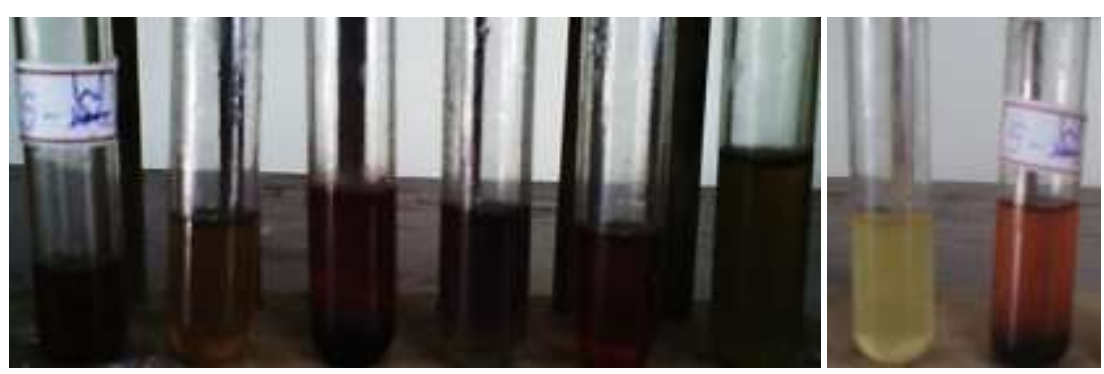

Figure 3.1: Phytochemical screening of Aqueous extract

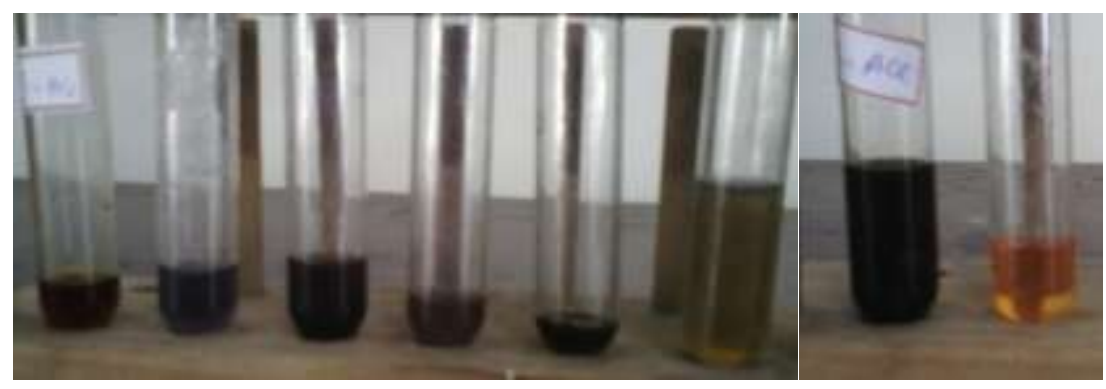

Figure 3.2: Phytochemical screening of Acetone extract

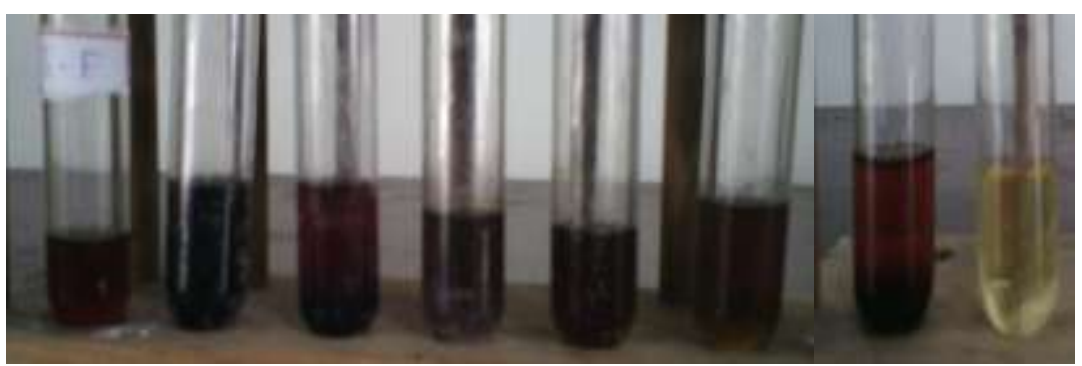

Figure 3.3: Phytochemical screening of Ethanol extract 
Characterisation of Phytochemical Constituents, Antioxidant and Anti Bacterial Properties of Red Strawberry against Klebsiella and Streptococcus

\subsection{Antibacterial Activity of fragaria $x$ ananassa}

\subsubsection{Sub culturing of microorganism}

The Klebsiella and Streptococcus organisms are sub cultured on a nutrient broth and incubated at $37{ }^{\circ} \mathrm{C}$ for 24 hours. The grown culture stored at 4으 $\mathrm{C}$ for further studies

\subsubsection{Zone of Inhibition}

The extracts of the fragaria $x$ ananassa had been tested for their antibacterial activities and an interesting antibacterial profile has been observed against Klebsiella and Streptococcus organisms. The extracts showed enormous activity against the two bacteria tested. The activities of extracts are mentioned in the terms of zones of inhibitions (mm). Experiment was done in triplicate. The results were shown in the Table 3.2 and Figure 3.4.

Table 3.2: Antibacterial Activity of fragaria x ananassa

\begin{tabular}{|c|l|c|c|}
\hline \multirow{2}{*}{$\begin{array}{c}\text { S. } \\
\text { No }\end{array}$} & \multirow{2}{*}{ Extracts } & \multicolumn{2}{|c|}{ Zone of Inhibition (mm in diameter) } \\
\cline { 3 - 4 } & & Klebsiella Sp. & Streptococcus \\
\hline 1 & Aqueous & $9.0 \pm 0.3$ & $6.0 \pm 0.2$ \\
\hline 2 & Acetone & $5.0 \pm 0.3$ & $3.0 \pm 0.1$ \\
\hline 3 & Ethanol & $2.0 \pm 0.1$ & $1.0 \pm 0.1$ \\
\hline
\end{tabular}

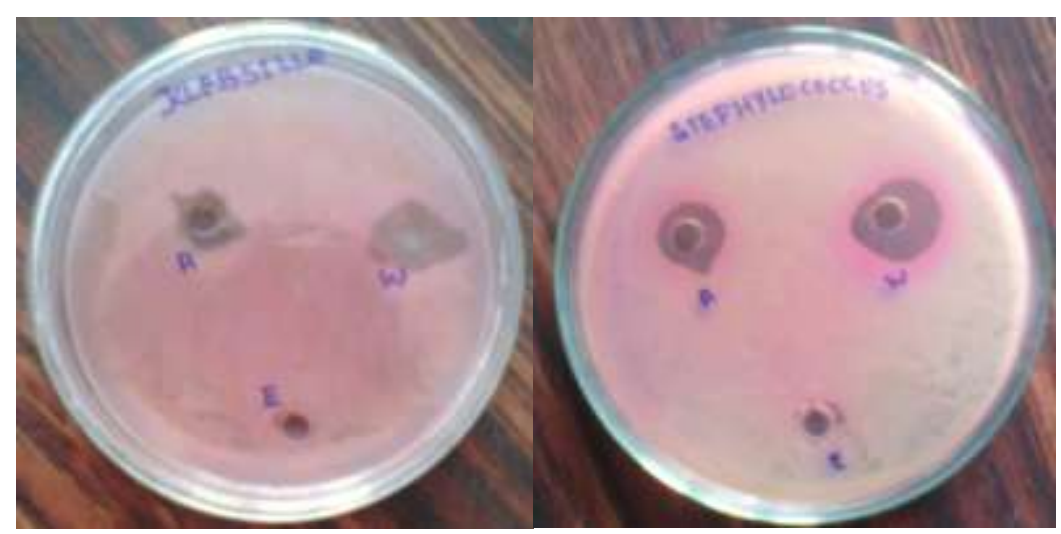

Figure 3.4: Antibacterial Activity of fragaria x ananassa

\subsection{Total Antioxidant Capacity of fragaria $x$ ananassa}

In this study, the Total antioxidant capacity was analysed. The antioxidant capacity was highly present in the acetone extract of fragaria $x$ ananassa fruit sample.

Table 3.2: Percentage of total antioxidant activities

\begin{tabular}{|c|c|}
\hline Extracts & Total Antioxidant capacity (\%) \\
\hline Water & $36 \pm 3.0$ \\
\hline Acetone & $52 \pm 2.8$ \\
\hline Ethanol & $42 \pm 2.0$ \\
\hline
\end{tabular}

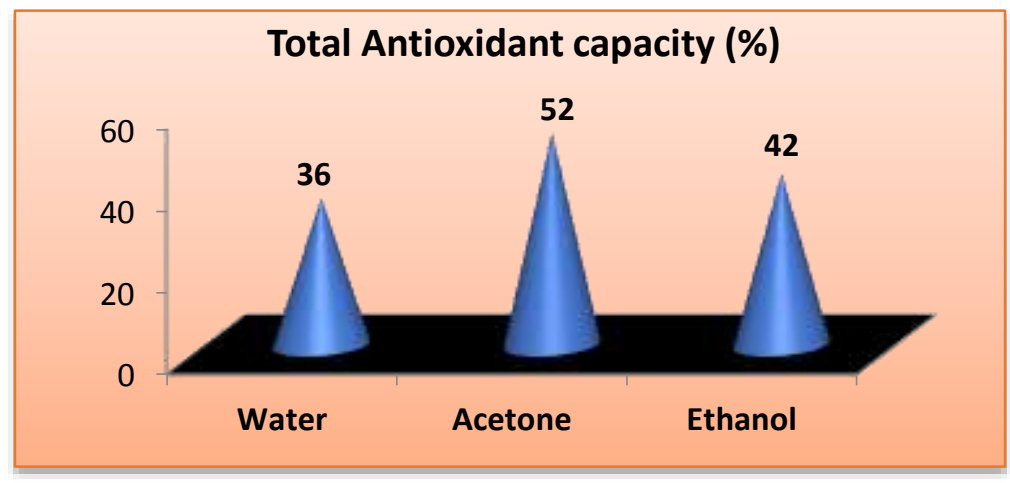

Figure 3.5: Shows the Total Antioxidant capacity 


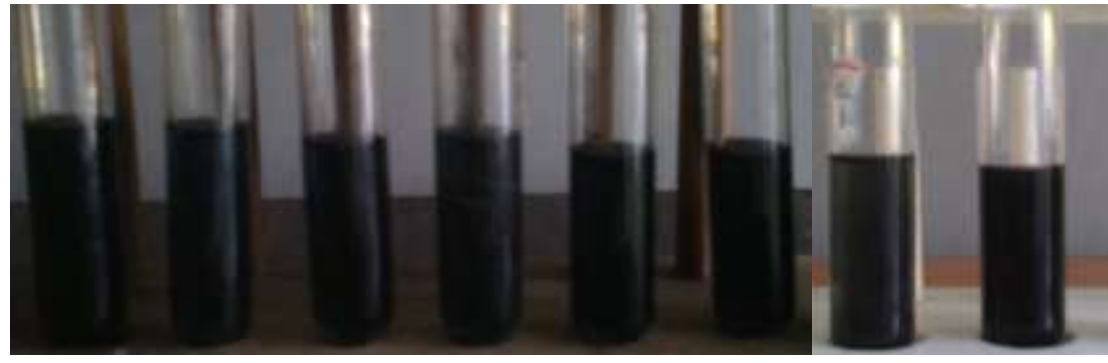

Figure 3.6: Indicates the presence of Total Antioxidants

\section{CONCLUSION}

The present study was carried out to determine the presence of bioactive constituents in fruit sample of fragaria $x$ ananassa. In this study, we also examined the antibacterial activity of fragaria $x$ ananassa fruit. Different solvent extract namely ethanol, acetone, aqueous extract were prepared from fragaria $x$ ananassa fruit and screened for its phytoconstituents. The Aqueous and Acetone extract was found to be the best source of various phytochemicals (Proteins and Amino acids) when compared with ethanol extracts. This study has confirmed that the antibacterial activity of fragaria $x$ ananassa extract against certain microorganisms. Results of this study showed that have found for that ethanol, acetone, aqueous extract of fragaria $x$ ananassa fruit sample was quite adequate inhibiting the growth of Streptococcus \& Klebsiella species. Total antioxidant capacities of fragaria $x$ ananassa fruit extract were analysed. High level of Total antioxidant capacity was found in Acetone extract of fragaria $x$ ananassa fruit. The results provide evidence that fruit sample of fragaria $x$ ananassa extracts might indeed be used as a potential source of effective natural antimicrobial and antioxidant agents in pharmaceutical and food industries.

\section{ACKNOWLEDGEMENT}

The authors thank the Management, Correspondent, Principal and Head of the Department of Biochemistry and other staff members of our department for providing the facilities and encouragement for this work. We were also grateful to our students for their involvement to complete this work

\section{BIBLIOGRAPHY}

1) A.R. Törrönen, Identification and quantification of phenolic compounds in berries of Fragaria and Rubus species (Family Rosaceae), J. Agric. Food Chem. 52 (2004) 6178-6187

2) Agustin ET (2007). Dayaantibakteriekstrakbuahmakutadewa (Phaleriamacrocarpa (Scheff) Boerl) terhadapbakteri Streptococcus alpha haemolyticus: penelitianlaboratoris. Bachelor Thesis. UniversitasAirlangga, Surabaya

3) Ali, Y. M., Iqbal, S. Z. A. Shah, and M. J. Ahmed. 2003. Effect of different combinations of nitrogen, phosphorous and farm yard manure on yield and quality of strawberry. Sarhad J. Agric. 19: 185-188

4) Ames, B.N.,M.K.Shigena, and T.M. Hagen.1993.Oxidants,antioxidants and the degenerative diseases of aging.Proc.natl.Acad.Sci.U.S.A.90;7915-7922

5) Anastasiadi M, Chorianopoulos NG, Nychas GJ, Haroutounian SA. Antilisterial activities of polyphenolrich extracts of grapes and vinification byproducts. J Agric Food Chem. 2009;57(2):457-63

6) Aravindaram K \&Yang NS, 2010. "Anti-inflammatory plant natural products for cancer therapy", Plantamedica, vol :76(11), pg : 1103-1117. Doi:10.1055/ s-0030-1249859

7) Bagchi D, Bagchi M, Stohssj, Das D k, Ray CA, et.al(2000) Free radicals and grape fruit proanthocyanidin extract; importance in human health and disease prevention J. Toxicol 148.187-197

8) Brooks JT, Bergmire-Sweat D, Kennedy M, Hendricks K, Garcia M, Marengo L, Wells J, Ying M, Bibb W, Griffin PM, Hoekstra RM, Friedman CR (2004). Outbreak of Shiga toxin-producing Escherichia coli 0111:H8 infections among attendees of a high school cheerleading camp. Clin Infect Dis 38, 190-198

9) D. Ivekovic, S. Milardovic, M. Roboz, B. S. Grabaric, The Analyst 130 (2005) 708

10) F. A. Tomas-Barberan, M. N. Clifford, J. Sci. Food Agric. 80 (2000) 1024

11) Grosvenor et al 1995; ratnakar and murthy 1995; silva et al 1996; David 1997; saxena 1997; nimri et al 1999; saxena and sharma 1999).

12) Gupta SS. Prospects and Perspectives of Natural Plant Products In Medicine. Indian Journal of Pharmacol. 1994; 26:1-12

13) Hakkinen, S.H. and A.R. Törrönen. 2000. Content of flavonols and selected phenolic acids in strawberries and Vaccinium species: Influence of cultivar, cultivation site and technique. Food Res. Intl. 33:517-524 
Characterisation of Phytochemical Constituents, Antioxidant and Anti Bacterial Properties of Red Strawberry against

Klebsiella and Streptococcus

14) Hausteen B. Flavonoids, a class of natural products of high pharmacological potency. Biochem Pharm. 1983; 32:11411148

15) Indian Horticulture Database. 2014. Ministry of Agriculture, Government of India, Gurgoan. Website: www.nhb.gov.in. 3307 Vijay Kumar, M. Pal, R.S. Singh, A.P. Singh, M.D. Ojha, R.K. Verma, R.B. Verma and P.K. Singh

16) Kammerer $D$, Claus $A$, Carle $R$ and Schieber A. Phenolic screening of pomace from red and white grape varieties (Vitis vinifera L.) By HPLC-DAD-MS/ MS. J Agric Food Chem 2004; 52:4360-4367. 7. Rodriguez MR, Peces RR, Vozmediano CJL, Gascuena MJ and Romero GE. Phenolic compounds

17) Lee S, San D, Ryu J, Lee YS, Jung SH, Kang J. Antioxidant activities of Acanthopanaxsenticosus stems and their lignin components. Arch Pharm Res. 2004;27,10610

18) Li H, Wang $X$ Li P, Li Y, Wang H (2008) Comparative study of antioxidant activity of grape (Vitis vinifera) Assessed different method.J food drug analysis1-7

19) Li H, Wang Z, Liu Y. Review in the studies on tannins activity of cancer prevention and anticancer. Zhongyao-Cai. 2003; 26(6):444-448

20) M. Kopjar, D. Subaric, V. Plizota, Glukozinolati: Biodostupnost i utjecajnazdravljeljudi, J. Hum. Nutr.Diet. 1 (2012) 2235. [2] K.R. Maatta-Riihinen, A. Kamal-Eldin

21) M. N. Clifford, A. Scalbert, J. Sci. Food Agric. 80 (2000) 1118

22) Ricardo da Silva JM. Monomeric, oligomeric, and polymeric flavan-3-ol composition of wines and grapes from Vitis vinifera L. Cv

23) Singliton VL, Tannins and the qualities of wines, in laks P.E. and Hemingway, R.W. (eds) Plant Polyphenols. Plenum Press, New York, NY; 1992.P.859-880.:6475-6481

24) Tsao R, Deng Z. Seperation procedures for naturally occurring antioxidant phytochemicals. Chromatogr B. 2004; 12:8599 